\title{
Entrevista com a escritora Clara Pinto Correia, concedida a Hércules Tolêdo Correia em Lisboa, janeiro de 2006.
}

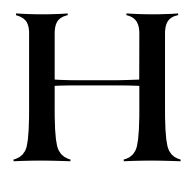

ÉRCULES - Primeiramente gostaria de agradecer a sua receptividade e a sua generosidade em conceder esta entrevista para um periódico acadêmico brasileiro. Para mim, é uma honra poder conversar com a senhora sobre o seu trabalho. Devo confessar que não conhecia seu trabalho até pouco tempo, mas neste mês em que estive em Portugal tive a oportunidade não só de ler alguns deles, mas de folhear outros e também de ver inúmeras referências à senhora e ao seu trabalho em várias bibliotecas e livrarias nas quais eu pesquisei aqui em Lisboa. Na listagem das suas publicações, identifiquei cerca de 40 obras literárias, sem considerar as suas publicações acadêmicas na área da Biologia. Gostaria, então, de iniciar esta conversa falando um pouco sobre a sua forma de trabalho, porque a senhora ainda é muito jovem para um currículo tão extenso.

CLARA - Olhe, eu tenho um problema grave: o meu grande bobby, aquilo que eu gosto realmente de fazer é escrever. Eu diria mesmo que o meu trabalho é também o meu hobby. É coisa que realmente me faz relaxar, descontrair. Uma forma de passar umas boas férias é estar a escrever um romance ou a trabalhar num bom projeto de investigação científica, em que as pessoas tenham um bom livro que vá ensinar coisas bonitas e criativas, e que elas ainda não saibam. Por exemplo, neste ano, no mês de agosto, meus filhos estavam com o pai nos Estados Unidos e eu não saí de Lisboa. Fiquei um mês inteiro a escrever um romance sobre o mito do judeu errante. Foram umas férias maravilhosas. Foi isso o tempo todo. Não precisava de mais nada. Gosto muito de ir à praia, adoro nadar, adoro água do mar, adoro praias desertas. De vez em quando eu dava uma escapadinha à praia - tenho uma casa na praia mas sequer fui lá. Curtia realmente era estar aqui sossegada, com a cidade deserta, de volta aos meus livros e a todos os planos. Assim vim a traçar 
essa história complicadíssima, de dois mil anos de curso pela Europa, histórias incríveis que fui pesquisar. Também estive em tudo quanto é biblioteca. Esses processos dão-me um prazer muito grande, assim como dá-me um prazer muito grande escrever poesia, como dá-me muito prazer escrever para crianças, como dá-me muito prazer a crônica, o ensaio.

Hércules - A senhora falou de escrever esses diversos gêneros literários. Uma questão que identifiquei, vendo a sua obra, foi exatamente isso, essa diversidade que vai do romance ao texto para teatro, há o texto acadêmico também. No âmbito literário tem romance, tem o romance policial, tem a poesia, tem o livro para criança. Como que é essa questão de trabalhar com os diferentes gêneros e não procurar uma especialização num determinado gênero?

Clara - Penso que cada idéia tem uma forma. Isto é como a pessoa encontrar a roupa ideal para vestir em cada determinado dia, conforme está o tempo e o que a pessoa irá fazer. Cada idéia que nós temos tem um formato que lhe assenta melhor. Gosto muito de, além de ter as idéias, ter o formato certo delas. Há uma idéia muito boa, por exemplo, que funciona muito bem como um conto. Mas não funciona bem como romance. Há uma idéia muito boa que dá uma bela história para crianças, mas seria desperdiçada como uma história para adultos. Há uma idéia que é boa para desenvolver como ensaio ou como pesquisa histórica, mas que não faz qualquer senso de sentido tentar ficcionalizar. Há idéias que dão libretos de ópera, porque são grandiosas. Uma coisa que dá-me imenso prazer é ter as idéias que tenho e procurar a roupa certa. Isso aí resulta uma grande diversidade na maneira como vou trazendo à luz e como vou fixando minhas idéias. Não que seja sempre imediatamente claro para mim. Muitas vezes tenho idéias, normalmente tenho milhões de idéias desafiando, a embolar-me meus pensamentos durante anos e anos e anos, até aparecer a forma, o formato ideal, depois começar a desenvolver aquilo que andou na minha cabeça durante anos. Isso é extremamente diferente. Mas é um gozo muito grande que se tem: já sei o que eu queria fazer e já sei como é que vai ser. Já sei como é que vai se chamar, sobretudo. É extremamente raro eu começar a escrever uma obra, seja qual for, sem saber qual vai ser o título. É raríssimo. Normalmente eu sei. Pode não acontecer, aconteceu pouquíssimas vezes, mas aconteceu, mudar o título ao meio, porque alguém me sugeriu um título melhor ou porque na minha própria cabeça apareceu um título melhor. Por exemplo, este romance que aqui está, que é o meu último, No meio do nosso caminho. Esse termo - "no meio do nosso caminho" - é do purgatório de Dante, que a certa altura, em sua 
Divina comédia, fala do purgatório como o meio do nosso caminho. Eu estava a falar no romance sobre pessoas que têm agora 40, 50 anos e estão no meio do seu caminho, estão entrando no purgatório e já sofreram imenso, já apanharam muita pancada, talvez ainda tenham o céu, mas não fazem idéia do que isso é, estão irritadas, estão muito cansadas e não fazem idéia para onde é que irão. Esse romance inicialmente ia se chamar Outra vez arroz. Estava num encontro acadêmico, as pessoas que estavam a organizar, como elas são sempre iguais, umas vezes elas dizem "ah, não, outra vez arroz."

Os organizadores acharam que o título poderia ficar brincalhão demais para a seriedade do tema. Que fazia sentido como um título brincalhão de colóquio acadêmico, interdisciplinar, mas não propriamente como previam para um romance. No meio do que eu estava a escrever ficou muito claro que já chamava-se era No meio do nosso caminho, que os personagens estavam se equiparando. Isso é espontâneo, não foi deliberado da minha parte, já que parte dos personagens se equiparavam psicologicamente, equiparavam psicologicamente a sua intenção a essa intenção do purgatório de Dante.

Hércules - Gostaria de tratar agora do livro Adeus, princesa, que é um romance policial. Uma questão que quero colocar é que, apesar de uma advertência do livro, de que é uma obra ficcional, parece que ele tem um certo estrato jornalístico.

Clara - O que se passa é que ela está construída como uma investigação jornalística. São dois jornalistas de Lisboa que vão ao Alentejo investigar um crime. Que depois nos dizem que não aconteceu. Quando eles lá chegam todos dizem: Não foram supostamente alguns inimigos da Alentejana que foram tomar mão com uma base da força aérea alemã, que existia em Beja, que agora já não existe. E quando eles lá chegam, toda gente diz: Não, não foi nada. Ela que não retornou, ela foi com os contrabandistas de drogas, quando contrabandistas aqui não tem. O mistério acaba por se tornar mais porque está toda a gente a mentir, quando é evidente que os amigos de Mitó, a tia e as pessoas amigas contam que seria lógico se o livro comentasse porque que toda gente está a fazer tanta questão de dizer "não". Quando o próprio Onildo aparece: "Não, fui eu que matei, claro que matei". Mas toda a gente diz "não". E o mistério acaba por se tornar mais porque toda a gente diz "não". Aliás, não é esclarecido pelo jornalista, que é um jovem ainda inexperiente. É esclarecido pelo fotógrafo. Mas basicamente é um romance sobre o fim, sobre o ocaso do 
sonho comunista muito concretamente, em Portugal, sobre o ocaso do sonho da reforma agrária no Alentejo, da terra, de quem trabalha.

Hércules - É comum a literatura policial na literatura portuguesa?

Clara - Devo dizer que nós lemos qualquer espécie de romances, entre eles os policiais. Considero algo maravilhoso. Gosto daqueles americanos, com um tiro, que descarrega. Mas acho que em matéria de romance policial os meus estão renovando. Usei foi o modelo do romance policial para escrever sobre um problema social. O editor da Relógio d'Água convidou-me para escrever um romance policial. Eu tinha essa idéia comigo. Eu vivi no Alentejo, pude estar de perto durante anos, e o impacto, todo o sonho comunista estava em desagregação. Porque os jovens já não se identificavam minimamente com as expressões dos pais. Resolvi usar o modelo do policial para desvendar um mistério, um crime, um amor possível, para falar sobretudo no mundo complexo da questão social que está por trás dessa história.

Hércules - Logo no início, é afirmado na advertência que é "um romance policial com coentros".

Clara - Ah, isso é uma graça em Portugal. Isso só uma pessoa portuguesa é que percebe. O coentro é uma erva aromática, extremamente intensa, que é usada em toda a região alentejana. Não há um único prato alentejano que não tenha coentro. O herói da história, que é um anti-herói, é muito engraçado, é um rapaz sem experiência nenhuma, muito feio, muito magrinho, não consegue fazer nada, etc., odeia coentro. Passa quatro dias no Alentejo e tem que comer coentro. Costumo dizer que as pessoas têm sempre essa mania de que os autores só escrevem autobiografias, que querem escrever suas vidas. Eu costumo dizer: "Sim, eu tenho um grande respeito, mas não sou autobiográfica com os meus romances". Eu odeio coentro. Aquele problema do Joaquim Peixoto é uma coisa autobiográfica. Eu passei muitas vezes muito mal no Alentejo por ser convidada para almoços e jantares em que uma pessoa me forçou a comer coentro. Odeio. Mas isso é uma brincadeira com as palavras. Mas que foi muito usado aqui. Toda vez que as pessoas falavam do Alentejo diziam, especialmente sobre os jogadores de futebol: "Este jogador tem coentro". Passou a ser uma maneira de as pessoas se referirem a qualquer coisa vinda do Alentejo. Se uma entrevistada disser que tem coentro é porque é uma pessoa alentejana. 
Hércules - Outra questão que gostaria de abordar é a sua relação com o cinema. Adeus, princesa, inclusive, já foi adaptado para o cinema.

Clara - Trabalhei em bastantes guiões (roteiros). Gosto muito de trabalhar em guiões, sobretudo em parcerias. Quer dizer, com pessoas que eu me dou muito bem, com coisas que já estão começadas. Gosto muito dessas coisas. Eu trabalhei em 4 ou 5 guiões, se não me engano. Aliás, recentemente estou envolvida em escrever mais um. Escrevi guiões das atrizes e entrei como atriz há dois anos num filme do Antônio Pimentel. Mas aí o guião não era meu. A personagem que o Antônio queria que eu fizesse era uma personagem muito engraçada e eu aceitei fazer com muito gosto.

Hércules - No filme Adeus, princesa o guião foi seu?

Clara - No Adeus, princesa o guião original era meu e do Joaquim Leitão, mas depois foi entregue a uma reescrita, porque deixou de ser uma produção portuguesa, passou a ser uma co-produção portuguesa-francesa-espanhola, tudo foi entregue aos espanhóis e aos franceses, eles reescreveram o guião todo. No fim eu não me identificava minimamente com ele, nunca me identifiquei com o produto final.

Hércules -Mas a história retratada no filme permanece a mesma do romance? Clara - Não, foi substancialmente alterada. Mas eu também penso que os autores dos romances não são as pessoas ideais para se pronunciarem sobre o que acham do filme, sobretudo quando é baseado em um romance. Obviamente, um filme e um romance não obedecem a uma mesma gramática. Como também escrevo guiões, sei que isso não se pode fazer da mesma maneira. Mesmo assim, podemos dizer que poder-se-ia ter feito um filme bastante bom. Como Portugal sai perdendo...

Hércules - Com relação ao livro Canções que já não existem, livro de poemas com fotografias, um trabalho em co-autoria com José Pedro Sousa Dias, queria saber um pouco mais sobre o processo de criação dessa obra.

Clara - O que está aí são as letras das canções. Algumas inclusive até já foram musicadas e foram gravadas em disco por alguns cantores e cantoras portugueses. Isto tem a ver com uma certa nostalgia. Eu penso que nós todos sentimos o que está descrito na introdução às canções. É sobre um tempo que já existiu, já deixou de existir, onde as coisas eram mais bonitas, mais lindas, mais dignas, menos ruborizadas, mais puras, 
onde se caminhava mais livremente pelos caminhos, onde todos nós carregávamos menos peso nos ombros. E onde a cultura tradicional ainda tinha um impacto muito grande, uma expressão muito grande. Era uma cultura muito rica e que se tem vindo a perder completamente.

Hércules - Podemos dizer que este é um livro nostálgico?

Clara - Sim, é nostálgico tanto nas canções quanto nas fotografias. Isto é Portugal, Portugal também é isto. Isto é, nossas imagens são de pessoas rindo, a testemunhar Portugal. Aliás, as fotografias da contracapa são de nós dois - Pedro e eu - em 1968, altura em que ambos iniciamos nosso processo de périplo pelo país, já tínhamos planos desenvolvidos em conjunto, aí é que ele tirava suas fotografias, na época já nos conhecíamos.

Hércules - Um outro livro que me chamou muito a atenção foi $A$ arma dos juizes. O prefácio de um biólogo sobre os efeitos da cafeína no corpo humano é muito interessante. Eu queria saber como é que foi a produção desse romance. Parece que ele foi muito bem recebido pela crítica.

Clara - Esse romance foi uma promessa que eu nunca deixaria de escrever, porque é muito complexo. Eu tinha na versão original 600 páginas e os editores pediram para cortar 100, porque estava complicado demais, estava grande demais. Acho que em termos editoriais ficaria melhor. Basicamente, a minha idéia era agarrar os personagens do Adeus, princesa. Porque eu tinha deixado, apesar de tudo, um estado grande de curiosidade. Porque o país de 85 era bastante puro, era um país bastante simples. Mesmo as suas grandes convenções sociais eram simples, pois nós temos que agüentar as geleiras e transplantá-las, ver o que é que tinha acontecido 17 anos mais tarde. 17 anos mais tarde já ninguém estava no Alentejo, estavam todos a viver nos subúrbios de Lisboa. Os subúrbios de Lisboa são um mundo em si mesmo, um mundo que não mais acaba, um mundo gigantesco, maior que Lisboa. As pessoas dizem, na maioria, que é horrível. E todas as pessoas têm problemas complexos, elas não se divertem, muitas ficam agressivas, não estão bem, não se sentem bem. O herói, Joaquim Peixoto, que é o mesmo do Adeus, princesa, desenvolveu entretanto uma dependência completa de drogas. Já não consegue fazer absolutamente nada sem tomar comprimidos. Mas também é um estudo sobre o que acontece ao organismo humano quando todas as nossas ações estão condicionadas por um comprimido que nós temos que tomar para fazer as coisas. Isso foi cuidadosamente estudado por meu psiquiatra. Passamos horas e horas estudando como é que tinha se desenvolvido o processo de 
auto-dependência aos comprimidos, para onde é que ele iria, até que ponto ele iria chegar e como é que ele ia acabar por ficar completamente amarrado num, entre aspas, estranhamento. Portugal hoje em dia tem que participar. Aliás, há tantos hoje em dia que outro dia me pararam na rua e me perguntaram: "Não foi a senhora que escreveu aquele livro A arma dos juizes?" Eu lhe disse que experimentei esses comprimidos todos, porque não conseguiria escrever o livro sem saber exatamente as sensações. É um caso difícil. A pessoa não consegue descrever como é que o fulano se sente, porque é que faz assim, não sei o que, se não experimenta, não é? E percebo muito bem que uma pessoa frágil em físico, que em nada sai bem, que perde a mulher mais bonita, que chega a viver com a mulher mais maravilhosa do mundo e a perde, fica dependente do uso das drogas pesadas. Pelo menos da primeira vez que eu tenha experimentado, elas fazem nos sentir maravilhosamente bem. Tenho por continuação que a pessoa se perde, se torna cada vez mais dependente, precisa cada vez mais de doses altas, cada vez mais se perde. É um romance muito triste. Como era uma continuação do Adeus, princesa, voltei a dar-lhe um roteiro policial. E é uma história para novela, e ia ser mesmo para novela. E é por isso que se chama $A$ arma dos juízes. É a história de um juiz que mata a mulher e o filho. A mulher que trabalha numa penitenciária de Lisboa, anda já a dizer que o juiz a vai matar. Porque ela observou que o filho era um homem de fazer bobagem, o filho primogênito, o grande herói do pai, era o herdeiro. $\mathrm{O}$ filho tem 18 anos. E o filho teve um acidente de moto e ficou paraplégico. E o pai nunca mais perdoou sua mãe, como se ela tivesse feito algo muito esquisito, era uma mulher brava e transformou-se em um tipo pavoroso, depois parece que passavam coisas lá em casa em que o senhor já me prometeu, portanto dormia com um armário encostado à porta, escrevia que não queria matar, que não sei o que, e a senhora chegava ao trabalho e dizia que ele a vai matar, vai matar, e ninguém fazia nada porque ele era juiz. O juiz tem direitos plenos acima de todas as outras pessoas. Ele acabou mesmo por matar a senhora. Matou a senhora, foi encontrada amarrada atravessada à cama, com vários tiros, e matou o filho e depois matou-se a si próprio. Com a arma dos juízes, porque o juiz tem todos os direitos de portar uma arma, que é algo completamente ilegal em Portugal para outras pessoas, só o juiz é que pode. Portanto, é também um bocado de discussão de poderes exagerados que os juízes têm. E o grande mistério da história é por que as reportagens quando escrevem sobre o crime nunca conseguem publicar nada. Nenhum órgão de comunicação social tem coragem de publicar a verdade sobre o crime.... 
Hércules - No Brasil, há um ditado que diz: "Metade dos juízes pensam que são Deus. A outra metade tem certeza de que é Deus".

Clara - Portanto é um romance que mistura muitas camadas de complexidade. E, portanto penso que as pessoas ficaram mais espantadas. Vendeu $60 \mathrm{mil}$ exemplares numa semana...

Hércules - É um índice altíssimo de vendagem, não?

Clara - Sim, sim, sim. Mas eu acho que isso é devido ao grande suspense sobre a obra.

Hércules - Ainda a propósito da crítica, eu gostaria de saber como é que o seu trabalho é recebido nas universidades portuguesas. Eu tenho notícias de que nos cursos de Estudos Portugueses, que equivalem aos nossos cursos de Letras, normalmente não são estudados os escritores vivos, aqui em Portugal. No Brasil, isso não é muito comum. Estudamos os autores contemporâneos. Há uma série de dissertações, de teses sobre os escritores vivos. Isso aqui em Portugal não é muito comum, não é?

Clara - Algumas pessoas apresentam teses, trabalhos, sobre escritores vivos, mas é mais um trabalho de experimentação. Muitas vezes são estrangeiros.

Hércules - Adeus, princesa é utilizado na Universidade Federal de Minas Gerais, nos cursos de Literatura Portuguesa Contemporânea.

Clara - Alguns dos meus livros para crianças também são usados nos manuais escolares. Alguns trechos.

Hércules - Na escola portuguesa de ensino básico é comum chamar escritores para se apresentarem? Por exemplo, a senhora costuma ser convidada?

Clara - Sim, sim, o tempo todo. Isto é complicado porque eu tenho que aprender a dizer "não". Porque aí o problema é o inverso, as questões são baseadas. Isso depende das minhas crenças. Porque eu tenho que falar e vou constranger as câmaras municipais e as instituições culturais. As pessoas querem sempre ver as pessoas, falar com elas, ter os livros, alguma coisa assim... Eu acho ótimo, mas...

Hércules - É impossível atender a todos, não é?

Clara - Tenho quinhentas coisas para fazer e tem a sua vida, não é? Eu tenho os meus filhos, tenho trabalho na universidade, tenho responsabilidades, e não são todas pagas. Tem tipos de coisas que a gente faz que não está ganhando, é complicado. 
Hércules - A senhora mencionou "trechos de livros publicados nos manuais didáticos". Mas como é a adoção dos livros, a leitura dos livros na íntegra, nas escolas? A senhora tem notícia disso?

Clara - O Adeus, princesa é um dos meus livros usados para alunos do décimo segundo ano, por exemplo. É muitas vezes usado como livro para os alunos estudarem para depois fazerem ensaios, depois fazerem dissertações. É sobretudo o Adeus, princesa, que passa diretamente na maioria dos alunos do décimo primeiro, décimo segundo "Estamos a fazer um trabalho sobre seu livro e precisávamos escrever", ou "queríamos entrevistá-la". Portanto, é esse o meu desafio.

Hércules - Sim. E de crianças também, não é? Por exemplo, a Canção dos dinossauros deve ser usado nas escolas.

Clara - Esse mais para adolescentes. Há uns que são mesmo para crianças.

Hércules - Há uma outra questão que me chamou a atenção, nem sei se caberia aqui. Como professora de Biologia, a senhora trabalha com a História do Pensamento Biológico, a História do Pensamento Científico.

Clara - Sim. Prestei exame em História da Ciência, sobretudo em História da Biologia, em Harvard, a partir de 1994. Hoje em dia a minha investigação é toda na área da História do Pensamento Biológico. Ainda tenho algumas publicações sobre clonagem até 1997, mas hoje não tenho mais, porque é tudo mesmo na área da História do Pensamento Biológico.

Hércules - Então, podemos ver aí uma aproximação com as Humanidades. Isso tem relação com o seu trabalho como escritora?

Clara - Sim, tem um projeto mesmo que eu desenvolvi desde muito cedo. É assim: penso que a área da História da Ciência hoje em dia está muito dominada pelos historiadores. Faz muita falta o olhar dos cientistas. Desde que eles aprendam a fazer História, não é? Porque há uma certa sensibilidade, há um feeling para a inclinação científica, para a visão científica nos tempos atuais. Portanto, quando acabei o curso de Biologia e comecei a trabalhar como assistente na faculdade, aos 25, 26 anos, já tinha mais ou menos claro como projeto de vida que iria fazer um doutoramento em Biologia, depois um pós-doutoramento, publicar alguns artigos e quando me sentisse bonificada como verdadeira cientista iria aprender a fazer História da Ciência e depois dedicaria a minha carreira à História da Ciência, mesmo tendo vindo do lado da Ciência e não do lado da História, embora pelo caminho 
de aprender a fazer história. Eu acho que não se pode fazer uma coisa que não se sabe fazer. Tem que aprender.

Hércules - Uma outra questão que está relacionada com isso, porque eu percebi a questão da ciência e religião, não é? cursos que a senhora tem dado. Como é essa questão da religião, para a mulher Clara Pinto Correia?

Clara - A mesma questão completamente científica. Eu sou católica, não tenho participação ativa, nunca tive, detesto. Acho que o Catolicismo precisava assim de uma grande injeção de sangue novo, de uma grande revitalização... Acho que a mensagem de Jesus está muito polida, isso continua muito válido. Entendo isso... isso não interfere na minha atividade como cidadã. Não interfere propriamente na minha atividade como historiadora, nem como cientista. Tenho que me concentrar na educação dos meus filhos. Quer dizer, mas isto tem mais a ver com o lado moral da minha vida, não com meu lado acadêmico ou artístico meu.

Hércules - Há ainda uma questão relacionada ao seu trabalho como jornalista. É que aos 20 anos a senhora já escrevia para jornais de Lisboa, não é?

Clara - Sim, sim. Eu estava a estudar... Eu saí da casa dos meus pais aos 17 anos. Foi quando foi possível alcançar de estudar... houve um período de transição, de abdução, em que ainda não existia décimo segundo ano. Essas aulas eram dadas todo verão. Como não eram por divisão, eram iguais no país inteiro. Porque se houvesse uma divisão eu não teria que obedecer, eu estava ansiosa por ter a minha própria vida. Portanto fui trabalhar em Trás-os-Montes, para uma residência de estudantes daquela escola. Comecei a estudar lá, depois fui para o Alentejo. Depois só voltei para Lisboa para entrar na Faculdade. Já não voltei para a casa dos meus pais. Fiquei vivendo de pequenos expedientes, não parava muito tempo em lugar nenhum... Eu também tinha 17 anos. Tive a minha primeira casa e depois aos 20 anos, num dia acabei por dar aulas no Liceu, no dia seguinte entrei para um semanário chamado O Jornal, que ficava no prédio onde eu vivia, porque eu tinha visto um anúncio na porta em que estavam a pedir estagiário. Eu precisava ganhar dinheiro, as aulas tinham acabado. Eu sei que no final de tudo foi para mim uma coisa estritamente pragmática. Depois parti para uma grande aventura de descoberta, de conhecimento, neste período de cinco anos que eu gostei muito, porque eu só saí do jornal quando eu acabei o curso inteiro, a Faculdade inteira. Esse tempo todo o resto do curso de Biologia eu fiz a trabalhar como jornalista e como jornalista começar em Portugal era extremamente 
diferente. Também transitei pelo rádio, pela televisão, fiz um pouco de tudo logo na juventude.

Hércules - No Liceu a senhora foi professora de Biologia?

Clara - Não, de Português. Os pais dos alunos ficavam muito surpreendidos, porque eles vinham falar comigo... eu tinha 19 anos. Eles diziam: "Ah, que engraçado é grandinha e está a estudar. Que estás a estudar? E eles olhavam para mim." Mas eu tinha estudado lá. Eles sabiam que eu era muito boa aluna de Português. E houve uma professora que ficou doente e precisou ser substituída. A minha antiga professora de Português sabia que eu andava à procura de emprego e me procurou perguntando se eu queria substituir a outra, eu fui, apresentei-me. Foi uma experiência interessante.

Hércules - Há um outro gênero que apareceu na sua produção, pouco comum nos dias de hoje, que é da fotonovela. No Brasil, a fotonovela era uma publicação muito popular até os anos 80 . Hoje, praticamente já não existe mais a fotonovela no Brasil. É a mesma concepção aqui em Portugal?

Clara - Sim, também. Era uma brincadeira... era usar a idéia da fotonovela para contar uma história com fotografias muito bonitas. Portanto, a fotonovela é uma espécie de conto. Um fotógrafo amigo fez as fotos e ficaram lindíssimas. E pronto, marcava com bolinhas e ajeitava cada pessoa aos papéis, para o texto. As fotografias iam mostrando depois as coisas que o texto conta.

Hércules - Quando pensei nesta entrevista também pensei no seu trabalho de atriz. O trabalho de atriz e o trabalho de escritor são dois trabalhos com o fingir. Fernando Pessoa já disse muito bem sobre o fingimento do poeta, do escritor. E o ator é aquele também que finge ser uma pessoa que não é, ser uma outra pessoa.

Clara - Em 2004, participei do filme "Kiss me", dirigido por António da Cunha Telles e distribuído pela Lusomundo Audiovisuais. Também apresentei programas de rádio e televisão, como o Música para camaleões, em 1986, na Rádio Comercial; o Rumo à lua, em 1996, pela RTP2; o Morfina, em 1999 e 2000, pelo canal CNL e o Travessa do cotovelo, em 2001, também pelo RTP2. Há uma única coisa que eu ainda não fiz, mas ainda hei de fazer: cantar. Eu gosto muito de cantar também. Eu canto bem. Mas ainda não se proporcionou, ainda não tive tempo 
Hércules - Vi que além da parte acadêmica, a senhora ainda ocupa cargos administrativos na Universidade, em coordenação.

Clara - Sim, eu fui vice-reitora da universidade durante um tempo. Inclusive tenho este defeito: eu detesto trabalho administrativo. Eu sou coordenadora de um programa de Biologia. Não é uma coisa que eu goste especialmente. Mas é preciso de pessoas mais experientes e então tive de pegar. 